\title{
Analyzing the quality and validity of Holep videos on social media
}

\author{
Emrullah Sogutdelen ${ }^{1}$ and Senol Tonyali ${ }^{2}$ \\ ${ }^{1}$ Bolu Abant İzzet Baysal University Faculty of Medicine \\ ${ }^{2}$ Istanbul University Istanbul Faculty of Medicine
}

November 20, 2020

\begin{abstract}
Purpose and Introduction: Social media users are gradually increasing and spending their time to gather much useful information for themselves. Here, we analyzed the quality of Holmium Laser Enucleation of Prostate (Holep) surgery videos on YouTube. Methods: The most viewed 98 videos were included in this study by the search for 'Holep' keyword on YouTube. The Journal of American Medical Association Benchmark Score (JAMAS) and Global Quality Score (GQS) were used to analyze the videos after performing validated Holep Scoring System Score (HSSS) by three surgeons to evaluate the technical quality of videos. Results: The videos included surgical technique (76.5\%) and uploaded by urologists $(63.3 \%)$ constituted the majority of videos. The median of JAMAS, GQS, and HSSS were 1 (0-3), 2 (0-4), and $1.5(0-11)$, respectively. The mean GQS and JAMAS of videos uploaded by academic centers was higher than those uploaded by commercials and urologists $(\mathrm{p}=0,01 ; \mathrm{p}=0.01$, respectively). The mean HSSS was lower in the videos uploaded in the last five years while JAMAS was higher $(\mathrm{p}=0.03 ; 0.005$, respectively). The mean GQS and HSSS of videos with higher likes were found statistically significantly higher ( $\mathrm{p}=0.01 ; \mathrm{p}=0.02$, respectively). Conclusion: Holep videos on YouTube are not enough worth to get proper information about the surgery. Videos uploaded by academic centers and in recent years provide relatively more valid information for patients and urologists. To increase the worth of information, online materials need to be checked for patients to access accurate, reliable, and appropriate healthcare information.
\end{abstract}

Analyzing the quality and validity of Holep videos on social media

Emrullah SOGUTDELEN ${ }^{1}$, Senol TONYALI ${ }^{2}$

Department of Urology, Bolu Abant Izzet Baysal University, Bolu, Turkey

Department of Urology, Istanbul University Faculty of Medicine, Istanbul, Turkey

Corresponding author: Emrullah Sogutdelen

E-mail: esdelen@gmail.com

ORCID ID: 0000-0002-1454-5672

Phone Number: +90 5063388456

Address: Department of Urology, Bolu Abant Izzet Baysal University, Bolu Abant Izzet Baysal Training and Resarch Hospital, 14280, Golkoy, Bolu, Turkey

\section{Acknowledgments}

None

ABSTRACT 
Purpose and Introduction: Social media users are gradually increasing and spending their time to gather much useful information for themselves. Here, we analyzed the quality of Holmium Laser Enucleation of Prostate (Holep) surgery videos on YouTube.

Methods: The most viewed 98 videos were included in this study by the search for 'Holep' keyword on YouTube. The Journal of American Medical Association Benchmark Score (JAMAS) and Global Quality Score (GQS) were used to analyze the videos after performing validated Holep Scoring System Score (HSSS) by three surgeons to evaluate the technical quality of videos.

Results: The videos included surgical technique $(76.5 \%)$ and uploaded by urologists $(63.3 \%)$ constituted the majority of videos. The median of JAMAS, GQS, and HSSS were $1(0-3), 2(0-4)$, and $1.5(0-11)$, respectively. The mean GQS and JAMAS of videos uploaded by academic centers was higher than those uploaded by commercials and urologists $(\mathrm{p}=0,01 ; \mathrm{p}=0.01$, respectively). The mean HSSS was lower in the videos uploaded in the last five years while JAMAS was higher $(\mathrm{p}=0.03 ; 0.005$, respectively). The mean GQS and HSSS of videos with higher likes were found statistically significantly higher $(\mathrm{p}=0.01 ; \mathrm{p}=0.02$, respectively).

Conclusion: Holep videos on YouTube are not enough worth to get proper information about the surgery. Videos uploaded by academic centers and in recent years provide relatively more valid information for patients and urologists. To increase the worth of information, online materials need to be checked for patients to access accurate, reliable, and appropriate healthcare information.

Keywords: Holep; Benign Prostatic Hyperplasia; BPH; Laser Prostatectomy, LUTS

\section{What is already known about this topic?}

The Internet has become one of the most addressing places to gather healthcare information. More than three and half billion social media users, expecting to increase four and half billion users in 2025, are spending an average of three hours to interact with each other and gather even healthcare information. The trend to assess YouTube videos in urology is tremendously increasing since the quality of videos of some urological subjects thought to be untrustworthy in terms of gathering the appropriate information.

\section{What does this article add?}

We aimed to assess the quality of mostly viewed Holep videos on YouTube using JAMAS for validity, GQS for usefulness, and HSSS for standardizing the videos developed to evaluate the significant features. Holep videos on YouTube are not enough worth to get proper surgical and technical information. Videos uploaded by academic centers and in recent years provide relatively more valid information for patients.

\section{Introduction}

Benign prostatic hyperplasia (BPH) is the leading morbidity which cause deterioration in the quality of life and serious cost burden especially in men over 70's [1,2]. Transurethral resection of the prostate (TUR-P) which is still current standard surgical procedure in men with bothersome symptoms and prostate size lower than $80 \mathrm{~mL}$, is used to relieve the bladder outlet obstruction (BOO) caused by the irregular proliferation of the prostate glands [3,4]. Either transvesical or transcapsular open prostate adenomectomy is one of the most invasive but effective surgical technique for prostate size higher than $80 \mathrm{~mL}$ and being used currently in many centers all around the world [5]. Newer technologies such as Holmium: Yttrium Aluminum Garnet (Holmium) laser enucleation of the prostate (Holep) has been widely used since 1995 when Gilling et al. enucleate whole prostate adenoma even in $200 \mathrm{~mL}$ and larger with lesser hospitalization time and comparable results to open prostatectomy as well as TUR-P [5-7].

Although the first invention of the internet dates back to the 1960's, its use in today's sense began in the 1980's [8]. Many platforms like social media which is a great area to interact with people have been jumping up exponentially since 2004. More than three and half billion social media users, expecting to increase four and half billion users in 2025, are spending an average of three hours to interact with each other and gather even healthcare information [9]. YouTube, one of the most used social media, is a well-known video-sharing 
site that has over two billion users every day and over one billion hours of videos [10]. YouTube allows unregistered users to easily access to high volumes of video content, but the quality, accuracy, and reliability of informational videos is a big problem as they are not controlled by competent people.

The trend to assess YouTube videos in urology is tremendously increasing since the quality of videos of some urological subjects thought to be untrustworthy in terms of gathering appropriate information [11,12]. In the present study, we aimed to assess the quality of mostly viewed Holep videos on YouTube using validated questionnaires and scoring systems developed to evaluate the significant features.

\section{Materials and Methods}

We conducted a YouTube search by using the keyword "Holep" on June 16th, 2020, and 100 most viewed videos were ordered. Nonrelevant or duplicated videos were excluded from the study and as a result, 98 videos were reviewed. After saving the search results in a playlist, three independent researchers viewed, analyzed, and scored the videos individually. Disperancies between rhe researchers were discussed and clarified. For scoring, five-point Global Quality Score (GQS) which validate whether the publication is useful or not [13] and four-point Journal of American Medical Association Benchmark Score (JAMAS) which validate the effectiveness and accuracy of publication [14] were used to assess the videos. Holep Scoring System (HSSS) which is 13 questions and 1 point of each, was created by the researchers based on the EAU guideline according to preoperative, intraoperative, and postoperative features of the Holep that should be present in video content (Table 1. ).

The videos were classified according to the source of upload (academic center, urologist, commercial, and other/unknown), video content (general information and surgical technique), type (live surgery, animation, and interview), country of origin (America, Europa, Asia, and Australia), and video language (English, other, and no audio). For each video, the number of views, likes, dislikes, upload date, the video length (second), and duration on YouTube (days) were collected.

All statistical analyses were performed using the SPSS 22.0 (IBM Corp., Chicago, USA) software. MannWhitney U-test and Kruskal-Wallis tests were used in the analysis. Descriptive statistics were presented as mean \pm standard deviation and median (minimum-maximum) to define the parameters. Spearman correlation test was used to evaluate the correlation between variables. $\mathrm{p}<.05$ was considered statistically significant.

\section{Results}

After the exclusion of two videos, 98 videos were evaluated. Mostly urologists (63.3\%) followed by academic centers $(21.4 \%)$ provided Holep videos on YouTube. Surgical technique $(76.5 \%)$ and general information about surgery (17.3\%) constituted the majority of videos. The majority of the videos $(51.0 \%)$ were not audible, $91.6 \%$ of the audio videos were in English, but $80.6 \%$ of all videos were without subtitles. Every four out of five videos consisted of live surgery followed by animation $(8.6 \%)$. Videos were sourced from Europe (48.9\%), Asia (25.5\%), America (19.1\%), and Australia (6.1\%), respectively. The median (min-max) of JAMAS, GQS, and HSSS were $1(0-3), 2(0-4)$, and $1.5(0-11)$, respectively. The sources, contents, and types of video are shown in Table 2 . and scores and video features are shown in Table 3.

The mean GQS and JAMAS of videos uploaded by academic centers was statistically significantly higher than videos uploaded by commercials and urologists $(2.38 \pm 0.97$ vs $1.67 \pm 0.88 ; 1.66 \pm 0.79$ vs $0.86 \pm 0.83$, respectively) ( $\mathrm{p}=0,01 ; \mathrm{p}=0.01$, respectively). The mean HSSS was significantly lower in the videos uploaded in the last five years while JAMAS was significantly higher (2.90土2.69 vs $1.85 \pm 2.14 ; 1.0 \pm 0.55$ vs $1.37 \pm 0.74$, respectively) ( $\mathrm{p}=0.03 ; 0.005$, respectively). There were no differences in JAMAS, HSSS, and GQS among uploaded countries. The mean GQS and HSSS values of videos with higher likes were found statistically significantly higher $(2.14 \pm 0.90$ vs $1.62 \pm 1.06 ; 2.86 \pm 2.78$ vs $1.75 \pm 1.91$, respectively) ( $=0.01 ; \mathrm{p}=0.02$, respectively). Videos including surgical technique had higher HSSS but lower GQS value than videos having other contents $(2.72 \pm 2.45$ vs $0.63 \pm 1.46 ; 1.66 \pm 0.82$ vs $2.60 \pm 1.23)$ ( $\mathrm{p}=0.001 ; 0.002$, respectively). Videos

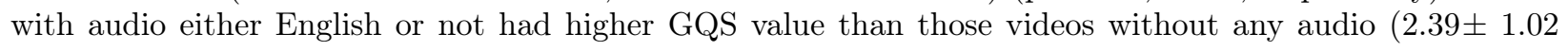


vs $1.40 \pm 0.72)(\mathrm{p}<0.001)$. A positive correlation was found in between HSSS and GQS, HSSS and JAMAS, and GQS and view numbers $(\mathrm{r}=0.238, \mathrm{p}=0.21 ; \mathrm{r}=0.206, \mathrm{p}=0.04 ; \mathrm{r}=0.255, \mathrm{p}=0.01$, respectively). All the comparisons of scores according to video features are shown in Table 4.

\section{Discussion}

The Internet has became one of the most addressing places to gather healthcare information. Social media platforms such as YouTube also make it possible to obtain health information and to understand it more easily with the help of videos. Even $90 \%$ of health care providers use social media with an average of 1 hour a day and $85 \%$ of health care practitioners agree that social media is a practical and effective tool for educational purpose [15]. YouTube videos have been evaluated in various medical sections including urology, rheumatology, orthopedic, and neurosurgery in terms of video quality [16]. Information on video quality about prostate cancer and BPH surgeries previously evaluated [11,12]. However, Holep videos specifically, on YouTube have not been considered by three different scores. In the present study, we aimed to evaluate the quality, informativity, and reliability of Holep videos on YouTube.

In our study, videos were commonly about surgical technique and uploaded by urologists with $1,2,1.5$ median JAMAS, GQS, and HSSS values, respectively. As it can be seen that all these scores were found too low to get adequate and accurate information about Holep since the uploaded videos were not in certain standards, were not checked by expert persons in their fields, and were not controlled by locally or globally healthcare authorities.

As GQS of videos indicate that videos are useful or not, the higher GQS found especially composed of highly liked videos and videos with audio even English or not. It seems that people prefer videos with audio and hit the like button if that video has quality enough to get appropriate Holep information. Videos provided by academic centers and uploaded in the last five years compared to older ones were found to have higher JAMAS indicating higher validity as it was expected that newer videos and point of expert's view in academic center influence the score since urologists especially in the academic centers know the questions that need to be answered and they know well what needs to draw attention in the video.

HSSS is a score that was created to standardize the video in which preoperative, operative, and postoperative information should be mentioned about Holep in the video. Therefore, higher HSSS was seen in the videos where the surgical technique was included. Surprisingly, despite the increase of research about the quality of publications or video contents recently, the HSSS of videos uploaded in the last 5 years found lower.

Our study has some limitations. Our sample includes a search of only one keyword and is a quite small size that collected mostly viewed 100 videos instead of all uploaded but we thought that our sample is sufficient to interpret and to makes inferences given the similar strategies on search [14,17]. Although interpretation of videos person-dependent, three independent urologists scored the videos to minimize the impact of personbased interpretation of the videos. Besides these limitations, we believe that these results will affect people who want to give medical information by videos and put a significant contribution to the current literature as this is the first study using quality and validity scores for specifically Holep videos on YouTube.

In conclusion, Holep videos on YouTube are not enough worth to get proper surgical and technical information. Videos uploaded by academic centers and in recent years provide relatively more valid information for patients. Healthcare professionals and society should work collectively to increase the truthfulness of videos containing healthcare informations since it negatively affects patient-physician communication [18]. Information obtained from social media is making a higher impact on patients. Therefore, it becomes more difficult to correct the effect of misinformation. Therefore, videos need to be more standardized so that the liners can access accurate, reliable and relevant information.

\section{Declarations}

Not applicable

\section{Funding}


This research did not receive any specific grant from funding agencies in the public, commercial, or not-forprofit sectors.

\section{Conflict of interest}

The authors declared that they have no conflict of interests.

\section{Availability of data and material}

The data that support the findings of this study are available from the corresponding author, E.S. upon reasonable request.

\section{Ethics approval}

Not applicable.

\section{Research Involving Human Participants and/or Animals}

Not applicable.

\section{Informed consent}

Not applicable.

\section{Authors' contributions}

S Emrullah: Data collection or management, Data analysis, Manuscript writing

T Senol: Data collection or management, Manuscript editing

\section{References}

[1] J.T. Wei, E. Calhoun, S.J. Jacobsen, Urologic diseases in America project: Benign prostatic hyperplasia, J. Urol. 173 (2005) 1256-1261. https://doi.org/10.1097/01.ju.0000155709.37840.fe.

[2] V. Kupelian, J.T. Wei, M.P. O’Leary, J.W. Kusek, H.J. Litman, C.L. Link, J.B. McKinlay, Prevalence of lower urinary tract symptoms and effect on quality of life in a racially and ethnically diverse random sample: The Boston Area Community Health (BACH) survey, Arch. Intern. Med. 166 (2006) 2381-2387. https://doi.org/10.1001/archinte.166.21.2381.

[3] M.E. Chua, J. Mendoza, M. See, E. Esmena, D. Aguila, J.M. Silangcruz, B.J. Reyes, S. Luna, M. Morales, A critical review of recent clinical practice guidelines on the diagnosis and treatment of non-neurogenic male lower urinary tract symptoms, Can. Urol. Assoc. J. 9 (2015) E463-E470. https://doi.org/10.5489/cuaj.2424.

[4] C. Gratzke, A. Bachmann, A. Descazeaud, M.J. Drake, S. Madersbacher, C. Mamoulakis, M. Oelke, K.A.O. Tikkinen, S. Gravas, EAU guidelines on the assessment of non-neurogenic male lower urinary tract symptoms including benign prostatic obstruction, Eur. Urol. 67 (2015) 1099-1109. https://doi.org/10.1016/j.eururo.2014.12.038.

[5] C. Gratzke, B. Schlenker, M. Seitz, A. Karl, P. Hermanek, N. Lack, C.G. Stief, O. Reich, Complications and Early Postoperative Outcome After Open Prostatectomy in Patients With Benign Prostatic Enlargement: Results of a Prospective Multicenter Study, J. Urol. 177 (2007) 1419-1422. https://doi.org/10.1016/j.juro.2006.11.062.

[6] Z. MA, A.-M. H, N. A, C. J, G. M, C. J, N. A, C. S, H. MR, Holmium laser enucleation of the prostate for very large benign prostatic hyperplasia ([?] 200 cc), World J. Urol. (2020). https://doi.org/10.1007/S00345020-03156-5.

[7] P.J. Gilling, C.B. Cass, M.D. Cresswell, M.R. Fraundorfer, Holmium laser resection of the prostate: Preliminary results of a new method for the treatment of benign prostatic hyperplasia, Urology. 47 (1996) 48-51. https://doi.org/10.1016/S0090-4295(99)80381-1. 
[8] Who Invented the Internet? | Britannica, (n.d.). https://www.britannica.com/story/who-invented-theinternet (accessed September 15, 2020).

[9] 10 Social Media Statistics You Need to Know in 2020 [Infographic], (n.d.). https://www.oberlo.com/blog/social-media-marketing-statistics (accessed September 1, 2020).

[10] YouTube statistics page, Basm - YouTube, (n.d.). https://www.youtube.com/about/press/ (accessed September 1, 2020).

[11] P. Betschart, M. Pratsinis, G. Müllhaupt, R. Rechner, T.R. Herrmann, C. Gratzke, H.-P. Schmid, V. Zumstein, D. Abt, Information on surgical treatment of benign prostatic hyperplasia on YouTube is highly biased and misleading, BJU Int. 125 (2020) 595-601. https://doi.org/10.1111/bju.14971.

[12] B. Carneiro, D.S. Dizon, Prostate Cancer Social Media: In YouTube We Trust?, Eur. Urol. 75 (2019) 568-569. https://doi.org/10.1016/j.eururo.2019.01.004.

[13] A. Bernard, M. Langille, S. Hughes, C. Rose, D. Leddin, S. Veldhuyzen Van Zanten, A systematic review of patient inflammatory bowel disease information resources on the world wide web, Am. J. Gastroenterol. 102 (2007) 2070-2077. https://doi.org/10.1111/j.1572-0241.2007.01325.x.

[14] W.M. Silberg, G.D. Lundberg, R.A. Musacchio, Assessing, Controlling, and Assuring the Quality of Medical Information on the Internet: Caveant Lector et Viewor - Let the Reader and Viewer Beware, Generations. 21 (1997) 53-55. https://doi.org/10.1001/jama.1997.03540390074039.

[15] A.G. Pizzuti, K.H. Patel, E.K. McCreary, E. Heil, C.M. Bland, E. Chinaeke, B.L. Love, P. Brandon Bookstaver, Healthcare practitioners' views of social media as an educational resource, PLoS One. 15 (2020). https://doi.org/10.1371/journal.pone.0228372.

[16] K.C. Madathil, A.J. Rivera-Rodriguez, J.S. Greenstein, A.K. Gramopadhye, Healthcare information on YouTube: A systematic review, Health Informatics J. 21 (2015) 173-194. https://doi.org/10.1177/1460458213512220.

[17] J.M. Morahan-Martin, How internet users find, evaluate, and use online health information: A crosscultural review, Cyberpsychology Behav. 7 (2004) 497-510. https://doi.org/10.1089/cpb.2004.7.497.

[18] A. Langford, S. Loeb, Perceived patient-provider communication quality and sociodemographic factors associated with watching health-related videos on YouTube: A cross-sectional analysis, J. Med. Internet Res. 21 (2019). https://doi.org/10.2196/13512.

Table 1. Holep Scoring System Score

Pre-operative evaluation

Was the age of the patient specified on video?

Were the patient's comorbid diseases stated on video?

Was the patient's medications (anticoagulant) stated on video?

Were the previous prostate surgeries specified on video?

Was preoperative abdominal imaging findings and/or prostate volume specified on video?

Was the uroflowmetric measurement and/or glob vesicale status specified on video?

During surgery

Were the instruments and sizes used specified on video?

Were the settings (power, frequency) of the laser specified on video?

Was the type of resection technique (bilobar, trilobar, en-bloc) utilized stated on video

Was the type and/or technique of morcellation given on video?

After surgery

Was the hospitalization period or discharge time specified on video

Was post-operative course and possible post-operative complications (i.e. incontinence) specified on video? 
Pre-operative evaluation

Was any radiological and uroflowmetric examination performed to assess the efficacy of operation specified on video?

Table 2. Sources, Contents, and Types of Videos

\begin{tabular}{llll}
\hline & & Frequency, $\mathrm{n}$ & Percent, \% \\
\hline Video source & Urologist & 62 & 63.3 \\
$(\mathrm{n}=98)$ & Academic center & 21 & 21.4 \\
& Private hospital & 5 & 5.1 \\
& Patient & 1 & 1 \\
& Commercial & 6 & 6.1 \\
& Others & 3 & 3.1 \\
Video content & Surgical technique & 75 & 76.5 \\
$(\mathrm{n}=98)$ & General information about surgery & 17 & 17.3 \\
& Advertisement & 5 & 5.1 \\
Video types & Patient experience & 1 & 1 \\
$(\mathrm{n}=93)$ & Live surgery & 79 & 84.9 \\
& Animation & 8 & 8.6 \\
& Interview & 5 & 5.4 \\
& Picture & 1 & 1 \\
\hline
\end{tabular}

Data are presented as frequency and percent. Abbreviations: n, number; \%, percent.

Table 3. Scores and Features of Videos

\begin{tabular}{llll}
\hline & & Mean \pm SD & Median (min-max) \\
\hline Video Scores & JAMAS & $1,22 \pm 069$ & $1(0-3)$ \\
$(\mathrm{n}=98)$ & GQS & $1,88 \pm 1,01$ & $2(0-4)$ \\
& HSSS & $2,29 \pm 2,43$ & $2(1-6)$ \\
Video Features & Video lenght $(\mathrm{s})$ & $986,7 \pm 957,7$ & $501(20-4579)$ \\
$(\mathrm{n}=98)$ & View & $6346 \pm 10286$ & $3026(378-57177)$ \\
& Like & $28,73 \pm 81,81$ & $8(0-684)$ \\
& Dislike & $1,98 \pm 4,63$ & $0(0-29)$ \\
& Duration $(\mathrm{d})$ & $1588,43 \pm 1068,1$ & $1299,5(85-3984)$ \\
\hline
\end{tabular}

Data are presented as mean $\pm \mathrm{SD}$ and median (min-max). Abbreviations: n, number; s, seconds; d, days; min, minimum; max, maximum; SD, standart deviation; JAMAS, Journal of American Medical Association Benchmark Score; GQS, Global Quality Score; HSSS, Holep Scoring System Score.

Table 4. Comparison of Scores According to Video Features

\begin{tabular}{llllllll}
\hline & & JAMAS & $\mathrm{p}$ & GQS & $\mathrm{p}$ & HSSS & $\mathrm{p}$ \\
\hline Upload Year & $2009-2015$ & $1(0-3) 1 \pm$ & $\mathbf{0 . 0 0 7}$ & $2(0-4)$ & 0.61 & $2(0-11)$ & $\mathbf{0 . 0 4}$ \\
& $\begin{array}{l}\text { (n=40) } \\
\text { median }\end{array}$ & 0.55 & & $1.82 \pm 0.93$ & & $2.9 \pm 2.69$ & \\
& $\left(\begin{array}{l}\text { min-max }) \\
\text { mean } \pm \text { SD }\end{array}\right.$ & & & & & & \\
& & & & & &
\end{tabular}




\begin{tabular}{|c|c|c|c|c|c|c|c|}
\hline & & JAMAS & $\mathrm{p}$ & GQS & $\mathrm{p}$ & HSSS & $\mathrm{p}$ \\
\hline & 2016-2020 & $1(0-3)$ & & $2(1-4)$ & & $1(0-9)$ & \\
\hline & $\begin{array}{l}(\mathrm{n}=58) \\
\text { median } \\
(\text { min-max }) \\
\text { mean } \pm \\
\mathrm{SD}\end{array}$ & $1.37 \pm 0.74$ & & $1.93 \pm 1.07$ & & $1.85 \pm 2.14$ & \\
\hline \multirow[t]{4}{*}{ Audio } & Yes $(n=48)$ & $1(0-3)$ & 0.72 & $1(0-4)$ & $<0.001$ & $1(0-11)$ & 0.49 \\
\hline & $\begin{array}{l}\text { median } \\
(\min -\max ) \\
\text { mean } \pm \mathrm{SD}\end{array}$ & $1.25 \pm 0.60$ & & $2.39 \pm 1.02$ & & $2.11 \pm 2.78$ & \\
\hline & No $(n=50)$ & $1(0-3)$ & & $1(0-4)$ & & $2(0-8)$ & \\
\hline & $\begin{array}{l}\text { median } \\
(\min -\max ) \\
\text { mean } \pm \\
\mathrm{SD}\end{array}$ & $1.20 \pm 0.78$ & & $1.4 \pm 0.72$ & & $2.46 \pm 2.09$ & \\
\hline \multirow[t]{4}{*}{$\begin{array}{l}\text { Video } \\
\text { Source }\end{array}$} & $\begin{array}{l}\text { Urologist } \\
(\mathrm{n}=62)\end{array}$ & $1.16 \pm 0.54$ & 0.01 & $1.67 \pm 0.88$ & 0.01 & $2.38 \pm 2.53$ & 0.82 \\
\hline & $\begin{array}{l}\text { mean } \pm \\
\mathrm{SD}\end{array}$ & & & & & & \\
\hline & $\begin{array}{l}\text { Academic } \\
\text { Center } \\
(\mathrm{n}=21) \\
\text { mean } \pm \\
\text { SD }\end{array}$ & $1.66 \pm 079$ & & $2.38 \pm 0.97$ & & $2.30 \pm 2.00$ & \\
\hline & $\begin{array}{l}\text { Commercial } \\
\text { and } \\
\text { Patient } \\
(\mathrm{n}=15) \\
\text { mean } \pm \\
\text { SD }\end{array}$ & $0.86 \pm 0.83$ & & $2.06 \pm 1.33$ & & $1.92 \pm 2.67$ & \\
\hline \multirow[t]{3}{*}{$\begin{array}{l}\text { Video } \\
\text { Content }\end{array}$} & $\begin{array}{l}\text { Surgical } \\
\text { technique } \\
(\mathrm{n}=75) \\
\text { mean } \pm \\
\text { SD }\end{array}$ & $1.24 \pm 0.67$ & 0.92 & $1.66 \pm 0.82$ & $<0.001$ & $2.72 \pm 2.45$ & 0.003 \\
\hline & $\begin{array}{l}\text { General } \\
\text { Informa- } \\
\text { tion } \\
(\mathrm{n}=17) \\
\text { mean } \pm \\
\mathrm{SD}\end{array}$ & $1.17 \pm 0.88$ & & $2.52 \pm 1.28$ & & $0.5 \pm 1.40$ & \\
\hline & $\begin{array}{l}\text { Advertisement } \\
\text { and } \\
\text { Patient } \\
\text { experience } \\
(n=6) \\
\text { mean } \pm \\
\text { SD }\end{array}$ & $1.16 \pm 0.40$ & & $2.83 \pm 1.16$ & & $1.0 \pm 1.73$ & \\
\hline
\end{tabular}


Data are presented as median (min-max) and mean \pm SD. Abbreviations: n, number; min, minimum; max, maximum; SD, standart deviation; JAMAS, Journal of American Medical Association Benchmark Score; GQS, Global Quality Score; HSSS, Holep Scoring System Score. One-way ANOVA and Tukey's post hoc tests were used to assess statistically significant differences, seen in bold, between groups.

\section{Hosted file}

Tables.pdf available at https://authorea.com/users/377491/articles/494145-analyzing-thequality-and-validity-of-holep-videos-on-social-media 